\title{
Pendekatan internet marketing: strategi pengembangan industri kecil menengah kerajinan
}

\author{
${ }^{1}$ Dahmiri*; ${ }^{2}$ Sylvia Kartika Wulan Bhayangkari; ${ }^{3}$ Wiwik Tiswiyanti \\ ${ }^{1,2)}$ Program Studi Manajemen FEB Universitas Jambi \\ ${ }^{3)}$ Program Studi Akuntansi FEB Universitas Jambi \\ *E-mail korespondensi: dahmiri@unja.ac.id
}

\begin{abstract}
This study aimed to determine the obstacles handicraft SMEs face in business development and to analyze the development strategy of small and medium handicraft industries with an internet approach. The sample of this research is Handicraft IKM entrepreneurs in districts/cities in Jambi Province. The data collection tool is in interview guides with both craft IKM actors and critical respondents. The types of data required are primary data and secondary data. Preliminary data were collected utilizing interviews and direct observation of SMI actors, while secondary data was obtained from literature and reports from related institutions. The data and information obtained are processed using qualitative data processing methods, then further analyzed to develop priorities for the company. The analytical tools used are Internal Analysis, SWOT Matrix. The results of the study concluded that the craft IKM development strategy with an internet marketing approach could be done by: 1) marketing through the internet in the form of websites, social media (Facebook, Twitter, Instagram), and marketplace; 2) excellent service; 3) simplify the administrative process; 4) create easy hints; 5) Provide affordable fees; 6) Immediately respond to complaints and complaints.
\end{abstract}

Keywords: Internet marketing, Development strategy, IKM crafts

\begin{abstract}
Abstrak
Tujuan penelitian ini adalah untuk mengetahui kendala yang dihadapi IKM kerajinan dalam pengembangan usaha dan menganalisis strategi pengembangan industri kecil menengah kerajinan dengan pendekatan internet. Sampel penelitian adalah pelaku usaha IKM Kerajinan yang terdapat di kabupaten/kota dalam Provinsi Jambi. Alat pengumpul data berupa panduan wawancara baik dengan pelaku IKM kerajinan maupun dengan key responden. Jenis data yang diperlukan adalah data primer dan data sekunder. Pengumpulan data primer dilakukan dengan cara wawancara dan pengamatan (observasi) pelaku IKM secara langsung sedangkan data sekunder diperoleh dari literature dan laporan lembaga terkait. Data dan informasi yang diperoleh diolah dengan menggunakan metode pengolahan data secara kualitatif, kemudian dianalisis lebih lanjut untuk menyusun sasaran yang merupakan prioritas bagi perusahaan. Adapun alat bantu analisis yang digunakan adalah Analisis Internal, Matriks SWOT. Hasil penelitian menyimpulkan bahwa strategi pengembangan IKM kerajinan dengan pendekatan internet marketing dapat dilakukan dengan cara : 1) lakukan pemasaran melalui internet baik berupa website, social media (facebook, twiter, instagram) maupun marketplace; 2) pelayanan prima; 3) permudah proses administrasi; 4) buat petunjuk yang mudah; 5) Berikan biaya yang terjangkau; 6) Segera merespon keluhan dan komplin.
\end{abstract}

Kata kunci : Internet marketing, strategi pengembangan, IKM Kerajinan 


\section{PENDAHULUAN}

Peran Industri kecil dan menengah (IKM) di Indonesia sangat besar dalam peningkatan ekonomi Negara, peneyerapan tenaga kerja dan sumbangannya terhadap Produk Domestik Bruto (PDB). Dari sisi jumlah IKM selalu tumbuh dari tahun ke tahun baik pada skala nasional maupun skala daerah termasuk di Provinsi Jambi. Namun demikian pada sisi kualitas IKM masih rendah, hal ini salah satunya ditandai dengan sulitnya perkembangan bahkan bertahannya berbagai jenis IKM termasuk juga IKM kerajinan.

Kontribusi IKM di sektor kerajinan terhadap PDRB di Provinsi Jambi paling besar dibanding IKM kelompok mode dan kuliner yaitu sebesar 9,008 \%, sedangkan penyerapan tenaga kerja sebesar 15.437 orang (Desmaryani, S., dkk, 2016). Besarnya kontribusi dan penyerapan tenaga kerja ini menjadi alasan untuk melakukan penelitian ini yang menitik beratkan kepada sektor kerajinan.

Persoalan yang dihadapi bukanlah semata-mata persoalan ketersediaan modal meskipun dana tetap diperlukan. Faktor-faktor lain adalah kemempuan kreatif dalam pengelolaan kelembanggan, input, proses, kualitas output yang relatif rendah. Dari sisi marketing kelemahan IKM kerajinan adalah rendahnya pemanfatan internet marketing.

Dari survey awal yang dilakukan ditemukan berbagai faktor yang mempengaruhi perkembangan IKM kerajinan antara lain SDA, SDM, teknologi, modal dan pemasaran. Oleh karena itu peneliti ingin menguji lebih lanjut mengenai pemasaran dalam kaitannya dengan perumusan strategi pengembangan IKM kerajinan. Strategi komunikasi pemasaran yang tepat digunakan untuk bisa meraih pangsa pasar yang dituju sehingga dapat meningkatkan penjualan (Kannan, P. K. (2017).

Salah satu media dalam era digitalisasi saat ini yang banyak digunakan pelaku IKM adalah Internet marketing seiring dengan semakin meningkatknya kemampuan pelaku usaha dan konsumen dalam mengikuti perkembangan digitalisasi. Internet marketing memungkinkan terjadinya komunikasi dan transaksi setiap waktu atau real time, bisa di akses ke seluruh dunia, dapat melihat berbagai jenis barang, kemudahan pemesanan dan kemampuan konsumen dalam membandingkan satu produk dengan produk lainnya (Kotler, P., et al., 2018).

Penggunaan internet marketing bagi IKM kerajinan akan lebih efektif dalam pengembangan usaha. Masalah yang dihadapi oleh pelaku IKM kerajinan di Provinsi Jambi salah satunya adalah kelemahan dalam pendekatan internet marketing, hal ini disebabkan oleh berbagai faktor antara lain kurangnya kemampuan SDM, rendahnya minat, ketebatasan dana dan kurangnya motivasi. Berdasarkan fenomena itulah maka penelitian ini menarik untuk dilakukan sebagai upaya menggali strategi yang tepat dalam pengembangan IKM kerajinan dengan pendekatan internet marketing.

Undang-undang No. 20 Tahun 2008 tentang UMKM, menyebutkan bahwa Usaha Kecil memiliki kriteria : (1) memiliki kekayaan bersih Rp 50.000.000,00 s.d. paling banyak Rp 500.000.000,00, dan tidak termasuk bangunan dan tanah; dan (2) hasil penjualan dalam satu tahun Rp 300.000.000,00 s.d. paling banyak Rp 2.500.000.000,00. Adapun kriteria Usaha Menengah yaitu: (1) memiliki kekayaan bersih Rp 500.000.000,00 s.d. paling banyak Rp 10.000.000.000,00 tidak termasuk bangunan dan tanah; dan (2) hasil penjualan dalam satu tahun $\mathrm{Rp} 2.500 .000$. 000,00 s.d. paling banyak $\mathrm{Rp}$ 50.000.000.000,00.

Peraturan Menteri Perindustrian RI Nomor 64/M-IND/PER/7/2016 Tentang Besaran Jumlah Tenaga Kerja Dan Nilai Investasi, yang dikatakan Industri adalah seluruh bentuk 
kegiatan ekonomi yang kegiatannya adalah mengolah bahan baku atau bisa juga memanfaatkan sumber daya industri yang pada akhirnya menghasilkan barang yang bernilai tambah atau menghasilkan manfaat lebih tinggi dari sebelumnya.

Pemasaran produk IKM lebih banyak bersifat lokal dan sistem penjualannya lebih utama dengan cara langsung dari produsen ke konsumen serta lebih banyak terjadi di pasar tradisional atau di toko milik pengusaha itu sendiri (Dewanti, I. S., 2010). Kelemahan IKM menurut ahli yang lain adalah dalam hal mendapatkan peluang pasar dan memperluas pangsa pasar IKM, lemahnya organisasi dan manajemen SDM, terbatasnya sumber-sumber modal, iklim usaha yang kurang kondusif, kerjasama yang belum luas, pembinaan pemerintah yang masih sangat kurang dan tidak terpadu dan masyarakat kurang peduli terhadap sektor usaha kecil (Malik, Z., 2013; Hameed, M. A., Counsell, S., \& Swift, S., 2012).

Suksesnya sebuah strategi yang disusun ditentukan oleh seberapa baik pemahaman mengenai konsep strategi pelaku usaha. Dalam sebuah perusahaan banyak strategi yang dapat diterapkan, antara lain : (a) Strategi manajemen; (b) Strategi investasi; (c) Strategi bisnis (Kapferer, J. N., 2012).

Kerajinan erat kaitannya dengan ekonomi kreatif, yang dapat iartikan sebagai bagian dari seni rupa terapan dimana titik temu antara seni dan desain yang sumbernya adalah dari warisan tradisi budaya atau ide komtemporer dengan menghasilkan karya seni, produk yang sifatnya fungsional dan benda dekoratif, serta bisa dikelompokan atas dasar material dan eksplorasi alat teknik yang dipergunakan, dan bisa juga dari tematik produknya (Kementrian Pariwisata dan Ekonomi kreatif, 2015).

Kerajinan dapat dikelompokkan sebagai berikut: 1).Berdasarkan bentuknya, dimana perbedaanya dilihat dari bentuk dua dan tiga dimensi. 2).Berdasarkan pelaku dan skala produksinya, dapat dibedakan menjadi limited edition craft, mass craft, dan individual craft. 3).Jika dilihat dari jenis produknya, maka kerajinan dibedakan art-craft dan craftdesign. 4).Dilihat dari bahan yang digunakan, yaitu ada kerajinan yang bahan bakunya dari keramik, dari kertas, dari gelas, dari logam, serat, tekstil kayu dan lain-lain.5). Jika dilihat dari teknik produksi, misalnya produk kerajinan dibuat dengan teknik pahat (ukir), slabing (keramik), tenun dan batik, rakit, cetak, pilin, an lain-lain.

Bisnis yang menggunakan internet marketing sebagai sarana pemasarannya memberikan perpsektif baru dalam hal jalur distribusi dan penjualan produk, sebuah bisnis bisa memasarkan produknya ke berbagai tempat di belahan bumi manapun dengan bantuan format digital dalam bentuk foto, kata-kata, dan video (Berthon, P., Hulbert, J. M., \& Pitt, L. F., 2011; Heding, T., Knudtzen, C. F., \& Bjerre, M., 2015). Beberapa karakteristik yang bisnis yang didukung dengan penggunaan internet marketing antara lain memberikan kenyamanan belanja di mana pelangan bisa berbelanja tanpa harus datang langsung ke took, jangkauan pasar pada media internet tidak memiliki batas area lokasi (Coughlan, Anderson, Stern, and El-Ansary, 2012). Kehadiran Internet saat ini berdampak sangat luar biasa terhadap berbagai jenis inustri baik skala kecil, menengah maupun besar. (Sagan dan Leighton, 2010; Glynn, C. J., Huge, M. E., \& Hoffman, L. H., 2012).

\section{METODE}

Penelitian ini masuk dalam kategori penelitian deskriptif kuantitatif (Scheurich, J., 2014). Jenis data berupa data primer dan data sekunder akan dikumpulkan secara sistematik dengan langkah-langkah sesuai prosedur. Data yang telah didapatkan kemudian diolah dengan metode pengolahan data dengan teknik kualitatif. Untuk menganalisis data 
akan menggunakan analisis Internal Matriks SWOT. Data primer akan didapatkan dengan cara wawancara dan pengamatan terhadap pelaku IKM yang dilakukan secara langsung. Data sekunder diperoleh dari literature dan laporan lembaga terkait.

Populasi merupakan wilayah generalisasi yang terbentuk dari obyek atau subyek dimana kualitas dan karakteristik yang dimilikinya bersifat khas yang ditentukan oleh peneliti guna dipelajari lalu kemudian pada akhirnya akan ditarik kesimpunlan (Creswell, J. W., \& Clark, V. L. P., 2017). Populasi penelitian ini adalah seluruh IKM kerajinan yang ada di Kabupaten/Kota dalam Provinsi Jambi yang berjumlah 1.079 unit. Sampel merupakan bagian dari jumlah dan karakteristik yang dimiliki oleh sebuah populasi (Terrell, S. R., 2012). Menurut Sevilla, C. G. et. al (2013) untuk menentukan ukuran sampel dari populasi digunakan rumus Slovin, sehingga diperoleh jumlah sampel 292 orang.

\section{Analisis data}

Untuk memperoleh gambaran profil IKM kerajinan digunakan analisis deskriptif. Aspek yang dianalisis meliputi karakteristik usaha yang ditekuni, ditinjau dari aspek proses bisnis internal dan aspek lingkungan eksternal serta aspek penggunaan internet marketing.

\section{Strengths-weaknesses-opportunities-threats (SWOT)}

Alat analisis yang sangat penting dalam menganalisis Kekuatan, Kelemahan, Peluang, dan Ancaman adalah Matrik SWOT yang diterapkan dalam empat tipe strategi yaitu SO (Strengths-Opportunities), WO (Weaknesses-Opportunities), ST (StrengthsThreats), dan WT (Weaknesses-Threats). (Gürel, E., \& Tat, M., 2017).

\section{HASIL DAN PEMBAHASAN}

\section{Karakteristik responden}

Usia pelaku usaha industri kecil dan menengah kerajinan lebih banyak pada usia antara 41-50 tahun yaitu sekitar 119 orang atau 41\%, dan berdasarkan tingkat pendidikan responden IKM kerajinan didominasi tamat SMA yaitu sebesar $57 \%$, pelaku IKM kerajinan dalam berusaha sumber dananya berasal dari dana pribadi yaitu sebsar 87 $\%$, mayoritas hasil produksi IKM kerajinan dipasarkan atau dijual sendiri oleh pelaku usaha tersebut, yaitu sebesar 57\%, pelaku IKM kerajinan lebih banyak mengunakan internet marketing lebih dari satu jenis media yaitu sebanyak $38 \%$, sedangkan yang hanya menggunakan instagram sebanyak $30 \%$. Adapun yang pling sedikit digunakan oleh pelaku IKM kerajinan adalah marketplace yaitu hanya $1 \%$.

\section{Hasil matriks internal eksternal (IE)}

Dari gambar 2. dapat dijelaskan bahwa: 1).Sel I, II atau IV adalah sel yang disebut tumbuh dan bangun (growth and build). Strategi insiatif (penetrasi pasar, pengembangan pasar dan pengembangan produk) atau integratif (integrasi ke depan, integrasi ke belakang dan integrasi horizontal). 2).Sel III, V atau VII dengan pengelolaan yang terbaik adalah strategi mempertahankan dan memelihara (hold and maintain) . 3).Sel VI, VIII atau IX mengambil hasil atau melepaskan (harvest and divest), strtegi yang tepat adalah memperkecil atau mengurangi usaha. 
Matriks SWOT memiliki 9 sel yang memberikan gambaran faktor-faktor yang menjadi kekuatan dan kelemahan yang dimiliki serta peluang dan ancaman yang dihadapi oleh IKM. Matriks SWOT berisi alternatif-alternatif strategi S-O, W-O, S-T dan W-T. alternatif-alternatif ini dikembangkan dari posisi IKM dalam matriks IE, gambar menunjukan titik kordinat matriks IFE dan EFE berada pada sel I yang berarti usaha berada pada kondisi tumbuh dan bangun. Strategi yang tepat yang dapat digunakan dalam pengembangan IKM kerajinan di Provinsi Jambi adalah strategi insiatif (penetrasi pasar, pengembangan pasar dan pengembangan produk).

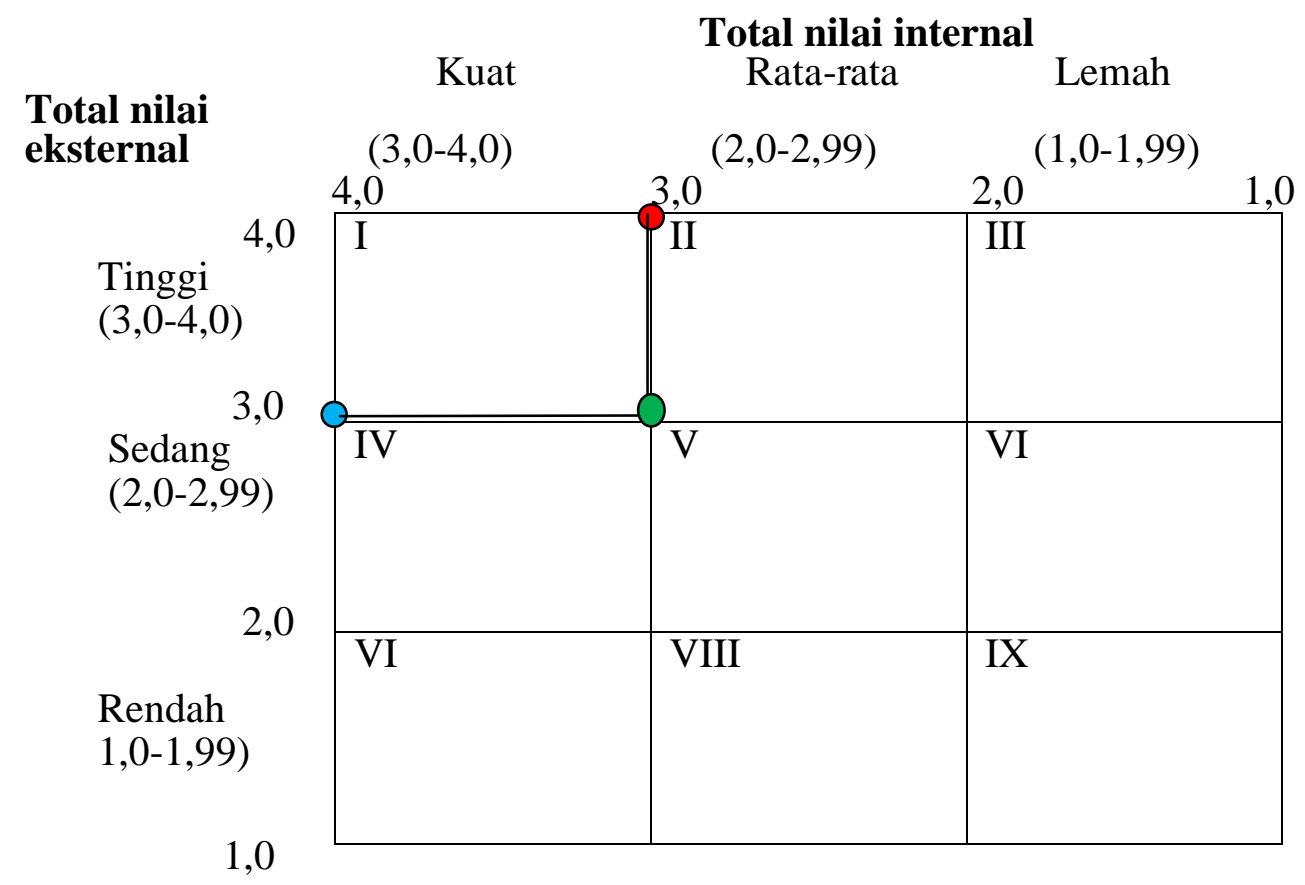

Gambar 2. Matriks internal eksternal

Starategi pengembangan IKM kerajinan di Provinsi Jambi berdasarkan posisi usaha yang terletak di Kuadran I adalah strategi Pengembangan pasar dengan memperluas jangkauan internet marketing, pengembangan produk, mempromosikan lebih banyak dan lengkap informasi produk, mempermudah proseur transaksi, promosi yang terus menerus dan lebih mengenal konsumen.

\section{Diagram kartesius analisis SWOT}

Selanjutnya nilai total skor masing-masing dapat dirinci, strength (+) 2,44, weakness (-) 0,5, opportunity 1.82, threats (-) 1,15, maka diketahui selisih total skor faktor strenght dan weakness adalah (+) 1,94, sedangkan selisih total skor faktor opportunity dan threat adalah (+) 0,67.

Dari Gambar 3 Diagram kartesius analisis SWOT menunjukan bahwa IKM Kerjinan di Provinsi Jambi berada Pada Kuadran growth yang mana kuadran tersebut weakness ($0,5)$, strenght $(+2,44)$, opportunity $(+1,82)$, threat $(-1,15)$ dimana ini merupakan situasi yang menguntungkan untuk IKM kerajinan karena memiliki peluang dan kekuatan sehingga dapat memanfaatkan peluang yang ada. Strategi pengembangan yang harus diterapkan dalam kondisi ini adalah mendukung kebijakan pertumbuhan yang agresif (growth oriented strategy). Kebijkan pertumbuhan yang agresif dapat disimpulkan sebagai suatu pemikiran yang logis, konseptualisasi hal-hal prioritas baik dalam jangka panjang 
maupun pendek yang dijadikan acuan untuk menentukan langkah ataupun tindakan yang akan dilakukan. Strategi pertumbuhan yang agresif dapat dimulai dengan meningkatkan penggunaan internet marketing demi memenuhi kebutuhan konsumen.

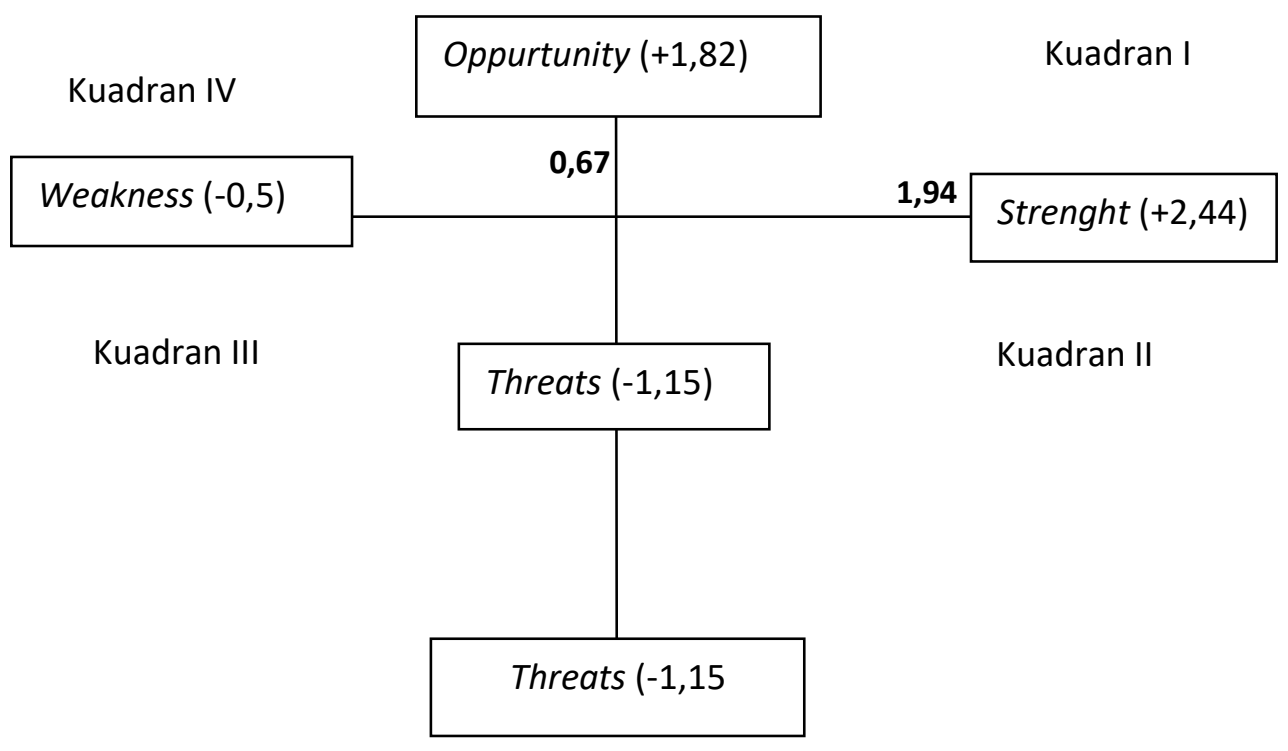

Gambar 3. Diagram cartesius analisis SWOT

\section{Matriks SWOT}

Matriks SWOT merupakan alat yang di pakai untuk mengukur faktor-faktor strategi IKM kerajinan. Matriks ini dapat menggambarkan secara jelas bagaimana peluang dan ancaman eksternal yang dimiliki. Matriks SWOT ini menghasilkan empat macam kemungkinan alternatif strategi yaitu strategi S-O, strategi W-O, strategi S-T, strategi WT. Hasil analisis SWOT dapat dilihat pada Tabel dibawah ini :

Tabel 2. Hasil analisis SWOT

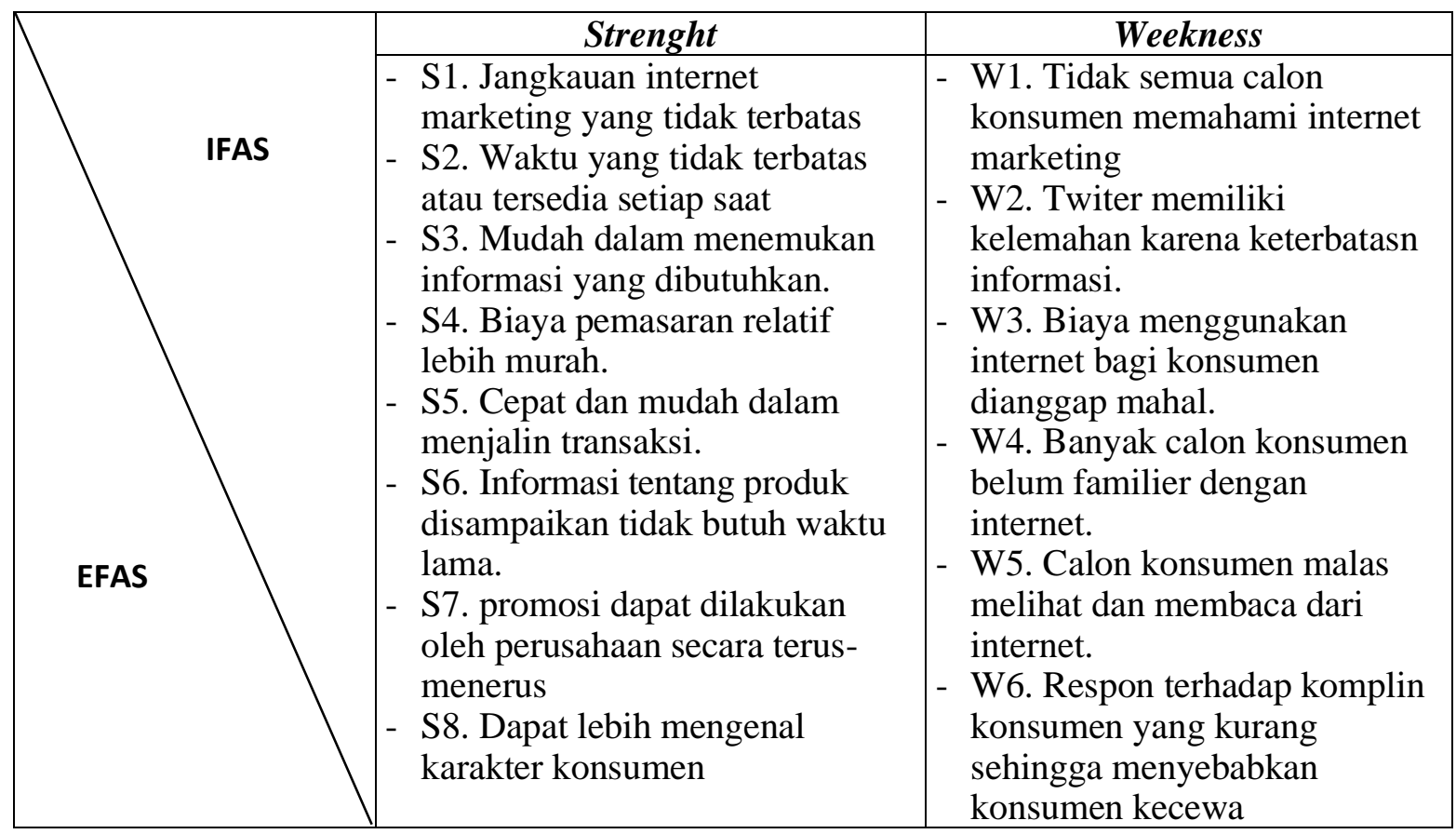




\begin{tabular}{|c|c|c|}
\hline Oppurtunity & Strategi SO & Strategi WO \\
\hline $\begin{array}{l}\text { - O1. Semakin } \\
\text { tingginya kebutuhan } \\
\text { informasi secara } \\
\text { online. } \\
\text { - O2. Terbukanya pasa } \\
\text { online yang semakin } \\
\text { potensial. } \\
\text { - O3. Pola konsumsi } \\
\text { masyarakat semakin } \\
\text { mengarah kepada } \\
\text { belanja online. } \\
\text { - O4. Teknologi } \\
\text { internet semakin } \\
\text { berkembang. }\end{array}$ & $\begin{array}{l}\text { - } \text { Melakukan internet marketing } \\
\text { secara massifdan terus menerus } \\
\text { seiring perkembangan teknologi } \\
\text { guna membuka peluang pasar } \\
\text { (S1,S2,O1, O2) } \\
\text { - Mempermudah menemukan } \\
\text { informasi dan berikan pelayanan } \\
\text { prima untuk meningkatkan } \\
\text { nama baik IKM } \\
\text { (S3,S4,S5,S6,O3) } \\
\text { - Melakukan promosi yang } \\
\text { gencar dan lakukan pendekatan } \\
\text { personal kepada konsumen } \\
\text { (S7,S8,O4) }\end{array}$ & $\begin{array}{l}\text { - Buat petunjuk yang mudah } \\
\text { bagi konsumen tentang } \\
\text { internet marketing yang dibuat } \\
\text { dan sampaikan kelemahan } \\
\text { (W1,W2,O1,O2) } \\
\text { - Berikan biaya semurah } \\
\text { mungkin bagi konsumen } \\
\text { dalam menggunakan internet } \\
\text { dan berikan pendidikan } \\
\text { tentang internet marketing } \\
\text { bagi konsumen (W3, } \\
\text { W4,O3,O4) } \\
\text { - Segera merespon keluhan } \\
\text { konsumen dan jaga nama baik } \\
\text { IKM (W5, W6, O3) }\end{array}$ \\
\hline Threat & Strategi ST & Strategi WT \\
\hline $\begin{array}{l}\text { T1. Usaha sejenis } \\
\text { sama-sama } \\
\text { menggunakan } \\
\text { internet } \\
\text { marketing. } \\
\text { - } 2 \text {. Ganggunan } \\
\text { penggunaan } \\
\text { internet berupa } \\
\text { hack dari para } \\
\text { hacker. } \\
\text { T3. Harus selalu } \\
\text { menguptode } \\
\text { informasi yang } \\
\text { membutuhan } \\
\text { keterampilan } \\
\text { T4. Membutuhkan } \\
\text { waktu khusus } \\
\text { untuk memantau } \\
\text { internet marketing }\end{array}$ & $\begin{array}{ll}\text { - } & \text { Permudah proses administrasi } \\
\text { dan meningkatkan kualitas } \\
\text { internet marketing } \\
\text { (S1,S2,S3,T1,T2) } \\
\text { - } \\
\text { Melakukan promosi dan } \\
\text { informasi produk secara } \\
\text { variatif, mempercepat proses } \\
\text { dan meningkatkan citra } \\
\text { IKM(S4,S5,T3) } \\
\text { - } \quad \text { Lakukan pelayanan yang } \\
\text { prima dan selalu mengupdate } \\
\text { informasi pada internet } \\
\text { marketing (S6,S7,S8, T4) }\end{array}$ & $\begin{array}{l}\text { - Segera merespon konsumen } \\
\text { yang komplin secara cepat dan } \\
\text { meningkatkan daya tarik } \\
\text { promosi (W2,W3,T1,T2) } \\
\text { - Mempermudah dan } \\
\text { mempersingkat waktu } \\
\text { administrasi dan selalu } \\
\text { meningkatkan citra } \\
\text { IKM(W1,W4, W5, W6, } \\
\text { T1,T3,T4) }\end{array}$ \\
\hline
\end{tabular}

Sumber: Data diolah, 2020

\section{HASIL DAN PEMBAHASAN}

Hasil analisis matriks swot menunjukan bahwa pengembangan IKM kerajinan melalui pendekatan internet marketing dapat ditentukan oleh kombinasi faktor internal dan eksternal, kombinasi kedua faktor tersebut di tunjukan dalam diagram hasil analisis SWOT sebagai berikut:

\section{Strategi SO (strenght-opportunity).}

Strategi ini merupakan gabungan dari faktor internal (Strenght) dan faktor eksternal (Opportunity), strategi ini dibuat berdasarkan pemikiran dengan memanfaatkan 
seluruh kekuatan untuk merebut dan memanfaatkan peluang sebesar-besarnya. Strategi SO yang di tempuh IKM kerajinan di Provinsi Jambi yaitu: 1).Melakukan internet marketing secara massifdan terus menerus seiring perkembangan teknologi guna membuka peluang pasar (S1,S2,O1, O2). 2).Mempermudah menemukan informasi dan berikan pelayanan prima untuk meningkatkan nama baik IKM (S3,S4,S5,S6,O3). 3).Melakukan promosi yang gencar dan lakukan pendekatan personal kepada konsumen $(\mathrm{S} 7, \mathrm{~S} 8, \mathrm{O} 4)$

\section{Strategi ST (strenght-threat)}

Strategi ini merupakan gabungan dari faktor internal (Strenght) dan faktor eksternal (Threat), strategi ini menggunakan kekuatan yang dimiliki IKM untuk mengatasi segala ancaman dari luar. Strategi ST yang ditempuh oleh IKM kerajinan di Provinsi Jambi yaitu: 1).Permudah proses administrasi dan meningkatkan kualitas internet marketing (S1,S2,S3,T1,T2), 2).Melakukan promosi dan informasi produk secara variatif, mempercepat proses dan meningkatkan citra $\operatorname{IKM}(\mathrm{S} 4, \mathrm{~S} 5, \mathrm{~T} 3)$, 3).Lakukan pelayanan yang prima dan selalu mengupdate informasi pada internet marketing (S6,S7,S8, T4)

\section{Strategi WO (weakness-opportunity).}

Strategi ini merupakan gabungan dari faktor internal (Weakness) dan Faktor eksternal (Opportunity), strategi ini diterapkan berdasarkan pemanfaatan peluang yang ada dengan cara mengurangi kelemahan yang dimiliki oleh perusahaan strategi WO yang diterapkan oleh IKM kerajinan adalah: 1).Buat petunjuk yang mudah bagi konsumen tentang internet marketing yang dibuat dan sampaikan kelemahan (W1,W2,O1,O2), 2).Berikan biaya semurah mungkin bagi konsumen dalam menggunakan internet dan berikan pendidikan tentang internet marketing bagi konsumen (W3, W4,O3,O4), 3).Segera merespon keluhan konsumen dan jaga nama baik IKM (W5, W6, O3)

\section{Strategi WT (Weakness-Threat).}

Strategi ini merupakan gabungan dari faktor internal (Weakness) dan faktor eksternal (Threat), strategi ini didasarkan pada aktivitas yang sifatnya defensive dan berusaha menghindari kemungkinan adanya ancaman dari luar untuk untuk mengurangi kelemahan perusahaan. Strategi WO IKM kerajinan di Provinsi Jambi yaitu: 1).Segera merespon konsumen yang komplin secara cepat dan meningkatkan daya tarik promosi (W2,W3,T1,T2), 2).Mempermudah dan mempersingkat waktu administrasi dan selalu meningkatkan citra IKM(W1,W4, W5, W6, T1,T3,T4)

\section{KESIMPULAN SARAN}

\section{Kesimpulan}

Lakukan kegiatan pemasaran melalui internet baik berupa website, social media (facebook, twiter, instagram) maupun marketplace secara gencar dan terus menerus mengikuti perkembangan teknologi informasi.

Utamakan pelayanan prima untuk meningkatkan nama baik IKM tanpa melihat latar belakang konsumen.

Permudah proses administrasi dan meningkatkan kualitas pemasaran melalui internet, selalu update data dan informasi dan variatif terhaap produk dan promosi yang ditawarkan. Buat petunjuk yang mudah bagi konsumen tentang internet marketing yang dibuat dan sampaikan kelemahan dan kekurangan produk. 
Berikan biaya yang terjangkau bagi konsumen dalam menggunakan internet dan berikan pendidikan tentang internet marketing bagi konsumen. Segera merespon keluhan dan komplin dari konsumen guna menjaga nama baik IKM kerajinan

\section{Saran}

IKM kerajinan di Provinsi Jambi dalam memilih pemasaran melalui internet harus mempertimbangkan berbagai aspek yaitu kemampuan SDM, kemampuan biaya dan konsistensi memelihara media yang telah dipilih.

Pemerintah daerah harus berperan lebih aktif dalam mendukung perkembangan IKM kerajinan misalnya menyediakan pinjaman dana berbunga rendah atau bantuan dana, membantu pemasaran produk kerajinan, memberikan pendidikan dan pelatihan penggunaan internet sebagai sarana pemasaran.

\section{DAFTAR PUSTAKA}

Berthon, P., Holbrook, M. B., Hulbert, J. M., \& Pitt, L. F. (2011). Brand manifold: Managing the temporal and socio-cultural dimensions of brands. In M. Uncles (Ed.), Perspectives on brand management (pp. 40-60). Prahran, Tilde University Press: Australia

Coughlan, A. T., Anderson, E., Stern, L. W., \& El-Ansary, A. I. (2012). Canais de marketing. São Paulo: Person. Northwestern University: Evanston

Creswell, J. W., \& Clark, V. L. P. (2017). Designing and conducting mixed methods research. Sage publications.

Dewanti, I. S. (2010). Pemberdayaan usaha kecil dan mikro: kendala dan alternatif solusinya. Jurnal Administrasi Bisnis, 6(2), 1-10.

Glynn, C. J., Huge, M. E., \& Hoffman, L. H. (2012). All the news that's fit to post: A profile of news use on social networking sites. Computers in Human Behavior, 28(1), 113-119.

Gürel, E., \& Tat, M. (2017). SWOT analysis: a theoretical review. Journal of International Social Research, 10(51).

Hameed, M. A., Counsell, S., \& Swift, S. (2012). A meta-analysis of relationships between organizational characteristics and IT innovation adoption in organizations. Information \& management, 49(5), 218-232.

Heding, T., Knudtzen, C. F., \& Bjerre, M. (2015). Brand management: Research, theory and practice. Routledge: United Kingdom.

Kapferer, J. N. (2012). The new strategic brand management: Advanced insights and strategic thinking. Kogan page publishers. Global Edition, 5th Edition. Kevin Lane Keller, Dartmouth College.

Kementrian Pariwisata dan Eknomi Kreatif, 2015, Kekuatan Baru Indonesia Menuju 2025.

Kannan, P. K. (2017). Digital marketing: A framework, review and research agenda. International Journal of Research in Marketing, 34(1), 22-45.

Kotler, P., Keller, K. L., Ang, S. H., Tan, C. T., \& Leong, S. M. (2018). Marketing management: an Asian perspective. Pearson.

Malik, Z. (2013). Ekonomika Industri Indonesia Menuju Negara Industri Baru (2030). Andi. Yogyakarta: Yogyakarta:

Peraturan Menteri Perindustrian Republik Indonesia Nomor 64/M-IND/PER/7/2016 Tentang Besaran Jumlah Tenaga Kerja dan Nilai Investasi.

Sagan, C., dan Leighton, T. (2010). The Internet and The Future of News. American Study 
of Arts and Sciences 139.2 (2010): 119-125.

Sevilla, C. (2013). Pengantar Metode Penelitian.: Universitas Indonesia: Jakarta

Terrell, S. R. (2012). Mixed-methods research methodologies. Qualitative report, 17(1), 254-280

Undang-undang Nomor 20 Tahun (2008) Tentang UMKM. Sekretariat Negara. Jakarta: Strategi pengembangan industri kecil menengah menuju industri kecil menengah kreatif di Provinsi Jambi, Balitbangda Provinsi Jambi: Jambi 